\title{
Bees prefer foods containing neonicotinoid pesticides
}

\author{
Sébastien Kessler\#, Erin Jo Tiedeken\#, Kerry L. Simcock, Sophie Derveau, Jessica \\ Mitchell, Samantha Softley, Jane C. Stout, and Geraldine A. Wright \\ \# These authors contributed equally to this work.
}

\begin{abstract}
The impact of neonicotinoid insecticides on insect pollinators is highly controversial. Sublethal concentrations alter the behaviour of social bees and reduce survival of entire colonies ${ }^{1-3}$. However, critics argue that the reported negative effects only arise from neonicotinoid concentrations that are greater than those found in the nectar and pollen of pesticide-treated plants ${ }^{4}$. Furthermore, it has been suggested that bees could choose to forage on other available flowers and hence avoid or dilute exposure ${ }^{4,5}$. Here, using a two-choice feeding assay, we show that the honeybee, Apis mellifera, and the buff-tailed bumblebee, Bombus terrestris, do not avoid nectar-relevant concentrations of three of the most commonly-used neonicotinoids, imidacloprid (IMD), thiamethoxam (TMX), and clothianidin (CLO) in food. Moreover, bees of both species prefer to eat more of sucrose solutions laced with IMD or TMX than sucrose alone. Stimulation with IMD, TMX, and CLO neither elicited spiking responses from gustatory neurons in the bees' mouthparts nor inhibited the responses of sucrose-sensitive neurons. Our data indicate that bees cannot taste neonicotinoids and are not repelled by them. Instead, bees preferred solutions containing IMD or TMX even though the consumption of these pesticides caused them to eat less food overall. This work shows that bees cannot control their exposure to neonicotinoids in food and implies that treating flowering crops with IMD and TMX presents a significant hazard to foraging bees.
\end{abstract}

Determining the impacts of pesticides on pollinators is important to resolve for the future of world food security. Pollinating insects like bees increase the yields of human crops, but in doing so, are inadvertently exposed to pesticides in floral nectar and pollen ${ }^{6,7}$. Several studies have concluded that bees exposed to sublethal doses of neonicotinoid pesticides in food have difficulty learning floral traits, feeding, navigating, and foraging $2,3,8-11$ and have impaired motor function ${ }^{12}$. These changes in behaviour often lead to colony failure ${ }^{2,3}$. This body of work has galvanized public concern over bee welfare, and in 2013, led to a two-year ban on the use of the three most common neonicotinoids (IMD, TMX, CLO) on flowering crops by the European Union. The agricultural importance of these pesticides has motivated

Reprints and permissions information is available at www.nature.com/reprints.Users may view, print, copy, and download text and data-mine the content in such documents, for the purposes of academic research, subject always to the full Conditions of use:http:// www.nature.com/authors/editorial_policies/license.html\#terms

Correspondence should be addressed to GAW (jeri.wright@ncl.ac.uk).

Author contributions: SCK performed the ephys experiments, spike sorted the ephys data and wrote portions of the manuscript, EJT, KLS, SD, JM, and SS performed the choice experiments, EJT and JS wrote portions of and edited the manuscript, and GAW designed the experiments, analysed all data, and wrote the manuscript.

The authors declare that they have no competing financial interests. 
agrochemical producers and government scientists to challenge this ban. Critics of lab-based experiments contend that such studies use food laced with neonicotinoid concentrations that exceed the levels found in nectar and pollen ${ }^{13}$, or give bees no choice of food solutions ${ }^{4,5}$. They propose that free-living bees and other insect pollinators could choose to avoid the nectar and pollen of pesticide-treated crops ${ }^{4}$ if pollinators are repelled by neonicotinoids ${ }^{14,15}$ and if alternative sources were provided such as field margins in agricultural settings.

These arguments require that pollinators are able to detect neonicotinoids in food in order to avoid exposure. We tested whether bees avoid sucrose solutions (i.e. nectar) containing neonicotinoids using a two-choice test designed to identify the bumblebee's gustatory detection thresholds for nectar toxins ${ }^{16}$. Individual foraging-age worker bumblebees or cohorts of 25 forager honeybees were housed in plastic boxes for $24 \mathrm{~h}$ and given access to two types of food tubes: one containing sucrose solution and one containing sucrose solution laced with a specific concentration of the IMD, TMX, or CLO. The concentrations used included values in the range reported from nectar and pollen (0.5-150 nM, Extended Data Table 1). Neither bumblebees nor honeybees avoided concentrations found within the naturally-occurring range (Figure 1a, b), even though high concentrations of TMX and CLO reduced their survival (Extended Data Fig 1). We also tested whether these pesticides inhibited the honeybee's feeding reflex (proboscis extension) or caused honeybees to retract the proboscis once extended ${ }^{17}$. None of the sucrose solutions containing IMD, TMX, or CLO affected proboscis extension or retraction (Extended Data Fig 2).

Unexpectedly, we observed that both bumblebees and honeybees showed a preference for solutions containing IMD or TMX over sucrose alone (Fig 1, Extended Data Tables 2, 3). Concentrations of IMD and TMX proximate to those found in nectar (1-10nM, Extended Data Table 1) were most attractive to bumblebees (Fig 1a) whereas honeybees were preferred to consume IMD and TMX across a broader range of concentrations (Fig 1b). The 'attractive' effect of IMD also depended on bee age: newly-emerged adult worker bumblebees and honeybees largely avoided 1-10nM IMD (Extended Data Fig 3a). In addition, the presence of neonicotinoids influenced the total amount of food consumed from both tubes during $24 \mathrm{~h}$ (Fig1 c,d). Bumblebees fed with IMD or CLO consumed less total food on average than those fed TMX or the sucrose control (Fig 1c, Extended Data Table 2); this effect has also been observed by others ${ }^{11,15}$. In contrast, the total food consumption of forager honeybees was reduced only when bees fed from solutions containing $100 \mathrm{nM}$ or $1 \mu \mathrm{M}$ TMX or CLO (Fig 2d, Extended Data Table 2). Thus, even in treatments where bees ate considerably less food in $24 \mathrm{~h}$, they still preferred to consume solutions containing IMD over sucrose alone. Bumblebees also consumed 1.5-10 fold more of the neonicotinoid-laced food than honeybees and were, therefore, exposed to higher pesticide doses (Extended Data Table 4).

Insects detect nutrients and toxins in food via gustatory neurons in hair-like sensilla on the proboscis (mouthparts) ${ }^{18}$. Toxic, non-nutritious compounds elicit spikes in 'bitter'-sensing neurons ${ }^{19,20}$ but can also be detected via suppression of the responses of sugar-sensing neurons ${ }^{21,22}$. Previous research has established that gustatory neurons located in sensilla on the honeybee's mouthparts are more sensitive to toxins in food ${ }^{17}$ than its antennae ${ }^{21}$ or $\operatorname{tarsi}^{23}$. If bees have mechanisms for detecting neonicotinoids, sensilla on the mouthparts 
should respond to these substances in the same way they respond to other toxins ${ }^{17}$. To test this, we recorded from gustatory neurons in sensilla on the galea (part of the proboscis) of bumblebees and honeybees using the tip recording technique (Fig $2 \mathrm{a}, \mathrm{b}$ ). Stimulation with IMD, TMX, or CLO in water did not elicit spikes from any of the neurons in the galeal sensilla of either bumblebees (Fig $2 \mathrm{c}$ ) or honeybees (Fig $2 \mathrm{~d}$ ) whereas stimulation with nicotine hydrogen tartrate (NHT), KCl, and sucrose did (Fig 2 c-f). This effect was the same for all three neonicotinoids in both bee species (Extended Data Table 5). To test whether neonicotinoids are detected via suppression of the neurons' responses to sugars, we applied sucrose solution laced with IMD, TMX, and CLO in an ascending series of concentrations from $1 \mathrm{nM}-1 \mu \mathrm{M}$ (Fig $2 \mathrm{~g}, \mathrm{~h}$ ). None of the concentrations we tested altered the spiking activity of sucrose-sensitive gustatory neurons in the bumblebees' or the honeybees' sensilla (Fig $2 \mathrm{~g}$, h, Extended Data Table 5). (Note: we confirmed that the mean spike rates reported in Fig $2 \mathrm{~h}$ were not a result of simultaneous excitation of bitter neurons and inhibition of sucrose-sensing neurons by manually spike sorting the records for IMD, Extended Data Fig 4). Furthermore, we found that both forager and newly-emerged honeybees lack taste neurons that respond to these compounds (Extended Data Fig 3b). Therefore, the behavioural data and electrophysiological recordings from mouthparts' gustatory neurons lead us to conclude that bumblebees and honeybees cannot taste neonicotinoids in nectar.

The preference of the bees in our assays for solutions containing IMD or TMX probably arises from the pharmacological action of these compounds on nicotinic acetylcholine receptors (nAChRs) in the bees' brains. It does not reflect a generalized enhancement of feeding because bees consuming these pesticides ate less food overall. Astonishingly, the preference occurred even when bees consuming these solutions were more likely to die. Our data may indicate, therefore, that IMD and TMX affect the neural mechanisms involved in learning about the location of rewarding food. Prior studies have demonstrated that freeflying honeybees prefer to collect sucrose solutions containing low concentrations of nicotine ${ }^{24}$. Nicotine also activates nAChRs ${ }^{25}$ expressed throughout the bee brain including the mushroom bodies required for learning, and memory ${ }^{26,27}$. It is notable that several studies have shown that chronic neonicotinoid administration impairs olfactory learning and memory in honeybees ${ }^{1,8,28,29}$. Our finding that bees acquire a preference for food laced with IMD or TMX could be explained by shorter neonicotinoid exposure in our experiments or by differential sensitivity of the nAChRs in the relevant brain regions necessary for each $\operatorname{task}^{26}$. It is also plausible that differential sensitivity of nAChRs accounts for our observed avoidance of newly-emerged bees towards solutions containing IMD.

Consumption of neonicotinoid-laced nectar by foraging bees could lead to higher attrition in this behavioural caste as well as reducing their foraging efficiency for pollen ${ }^{2,30}$. This would have a greater impact on wild bee colonies with relatively few foragers than on domesticated honeybees. If foragers prefer to collect nectar containing IMD and TMX, they will also bring more neonicotinoid-laced food back to the colony. For these reasons, whole colonies could be exposed to higher levels of these pesticides in the field than previously predicted. Mitigation strategies that rely on planting alternative sources of nectar and pollen, therefore, might not be enough to decrease the risk of poisoning pollinators with pesticides. Instead, long-term changes to policy that include reducing their use may be the only certain means of halting pollinator population decline. 


\section{Methods}

\section{Behavioural two-choice assays}

Experiments were performed at Trinity College, Dublin with Bombus terrestris dalmatinus (Unichem Ltd, Co. Dublin, Irish distributor for Koppert). Colonies were maintained at 25-30 ${ }^{\circ} \mathrm{C}$ in $24 \mathrm{~h}$ darkness and fed commercial pollen and Biogluc (Agralan Ltd, Swindon) bee food ad libitum. Experiments were also performed at Newcastle University, Newcastle upon Tyne with Bombus terrestris audax (Biobest, Belgium) and Bombus terrestris terrestris (Koppert Biological Systems, NATURPOL, Netherlands). Bees from 3-5 different colonies were used for each neonicotinoid. Individual worker bumblebees were collected as they tried to exit the colony. For the experiments with newly-emerged bumblebees, colonies were monitored for newly emerged bees daily; newly-emerged adults were identified by their pale colour. These bees were extracted using forceps from within the colony. As previously described in Tiedeken et al. (2014) ${ }^{16}$, individual bumblebees were cold anesthetized, weighed and sex-determined, and transferred to individual $650 \mathrm{ml}$ plastic containers $(160 \times 110 \times 45 \mathrm{~mm})$. Containers were fitted with three $3 \mathrm{ml}$ feeding tubes, inserted horizontally. Feeding tubes had four $2 \mathrm{~mm}$ holes so bees could alight on the tubes and feed from the openings. The feeding tubes contained one of three solutions: (1) deionized water; (1) $0.5 \mathrm{M}$ sucrose; or (3) $0.5 \mathrm{M}$ sucrose with a specific concentration of a neonicotinoid compound. Whether or not the bee was alive was noted $24 \mathrm{~h}$ after start of experiment. Bees that did not drink from either tube were excluded from the final analysis; the total number of these subjects was never greater than 3 per treatment (note: these subjects were always dead and likely to have died from stress or other causes).

Experiments with honeybees (Apis mellifera var Buckfast) were performed at Newcastle University during the summer months using 2 free-flying outdoor colonies originally obtained from the UK's National Bee Unit (Sand Hutton, Yorkshire). Foraging adult worker honeybees were collected at the colony entrance as they returned from foraging; newlyemerged adult workers were collected from brood comb as they emerged in a purpose built box kept in an incubator at $34^{\circ} \mathrm{C}$. Bees were cold anesthetized prior to placing in rearing boxes. Cohorts of 25 bees were placed in rearing boxes as previously described in Paoli et al. $(2014)^{31}$. Four food tubes (as described above) were provided: (1) one with deionized water; (2) two with $1 \mathrm{M}$ sucrose; (3) two with $1 \mathrm{M}$ sucrose containing a specific concentration of a neonicotinoid. The number of bees alive in each cohort was counted at the time of measurement of the food consumption ( $24 \mathrm{~h}$ later).

All of the two-choice experiments were performed experimenter-blind (except IMD with bumblebees). Three neonicotinoid pesticides, imidacloprid (IMD), thiamethoxam (TMX) and clothianidin (CLO), were used in the experiments (Pestanal@, Sigma-Aldrich). The neonicotinoid concentrations used were $1 \mathrm{nM}, 10 \mathrm{nM}, 100 \mathrm{nM}, 1 \mu \mathrm{M}$ (see Extended Data Table 2 for conversions to $\mathrm{ppb}$ and $\mathrm{ng} / \mathrm{bee}$ ). Bees were kept in continuous darkness for $24 \mathrm{~h}$ at constant temperature and $60 \% \mathrm{RH}$ (bumblebees: $28{ }^{\circ} \mathrm{C}$; honeybees: $34{ }^{\circ} \mathrm{C}$ ). Control boxes identical to the experimental boxes (without bees) for each neonicotinoid treatment were placed in the incubator simultaneously with the experiments to measure the rate of evaporation from the food solutions. Feeding tubes were weighed, placed in the 
experimental boxes with the bees for $24 \mathrm{~h}$, and then removed and weighed a second time.

The position of the treatment tubes was randomized across subjects. The amount of solution consumed was determined as the difference in the weight of each tube after $24 \mathrm{~h}$; the average value for the evaporation control for each treatment was subtracted from this final value for each tube. For bumblebees, sample sizes were: IMD: $1 \mathrm{nM}=57,10 \mathrm{nM}=66$, $100 \mathrm{nM}=65,1 \mu \mathrm{M}=66$; $\mathrm{TMX}: 1 \mathrm{nM}=38,10 \mathrm{nM}=39,100 \mathrm{nM}=36,1 \mu \mathrm{M}=40$; CLO: $1 \mathrm{nM}$ $=57,10 \mathrm{nM}=59,100 \mathrm{nM}=48,1 \mu \mathrm{M}=62$. For honeybees, $\mathrm{N}=40$ cohorts of 25 bees $/$ treatment. Sample size was chosen as N $\geq 40$ based on previous work ${ }^{16}$; sample size varied because some individuals died from unknown causes at the start of the experiments.

\section{Honeybee antennal and mouthparts assays}

Honeybees were collected at the entrance of an outdoor colony as they returned from foraging, cold anesthetized, and harnessed as described in Bitterman et al. (1983) ${ }^{32}$. Each was fed $1 \mathrm{M}$ sucrose to satiety and left overnight in a humidified plastic box and assayed $18 \mathrm{~h}$ later. Briefly, two assays were employed: one in which individual honeybees were lightly tapped on the antenna with a stimulating solution (e.g. sucrose) to elicit the feeding reflex (i.e. proboscis extension reflex, or PER) and a second assay in which a droplet of stimulating solution was placed at the end of the extended proboscis to test whether bees would consume it (further details described in Wright et al. 2010 ${ }^{17}$ ). Stimulating solutions were $1 \mathrm{M}$ sucrose containing one of the following concentrations ( $1 \mathrm{nM}, 10 \mathrm{nM}, 100 \mathrm{nM}, 1$ $\mu \mathrm{M}, 10 \mu \mathrm{M}$ ) of one of three neonicotinoids (IMD, TMX, CLO).

\section{Electrophysiology}

Individual bumblebees (B. terrestris audax and B. terrestris terrestris) and honeybees were cold anesthetized on ice for 3-5 min, and then restrained in a metallic restraining harness as described in Bitterman et al. (1983) ${ }^{32}$. To avoid any movements of the mouthparts during recordings, muscles that trigger proboscis extension were cut by making an incision at the level of the proboscis fossa. Each galea was fixed with a curved metallic wire pinned into dental wax.

Electrophysiological recordings were made from taste neurons located in the first 11 sensilla chaetica $^{33}$ located at the tip of the galea on the honeybee's proboscis as in Wright et al. $(2010)^{17}$ and in the first 6 sensilla in bumblebees. Bees were electrically grounded via a chlorinated silver wire inserted into the head. Sensilla were visualised under a microscope (M205C, Leica, Germany) at a magnification of 256×. To record from gustatory neurons, we used a method first described by Hodgson et al. (1955) ${ }^{34}$. Sensilla were stimulated with a recording borosilicate electrode (50 $\mathrm{mm}$ long, $20 \mu \mathrm{m}$ diameter) containing the test compounds diluted in demineralized water. The recording electrode was connected via a chlorinated sliver wire to a high impedance "non-blocking" pre-amplifier (TastePROBE, Syntech, Germany) ${ }^{35}$ mounted on a motorized micromanipulator (MPC-200, Sutter Instrument, USA). The signal was further amplified and filtered with an AC amplifier (model 1800, gain: 100×, band-pass filter: 10-1000 Hz, A-M Systems, USA). Each stimulus trial was digitized (sampling rate $10 \mathrm{kHz}, 16$ bits; DT9803 Data Translation), stored on a computer with dbWave software (version 4.2014.3.22) and analysed with Matlab R2012b (version 8.0.0.783) utilising PeakFinder with fixed thresholds as the peak detection 
algorithm (PeakFinder.m., Mathworks file ID: 25500). Recordings were made for $2 \mathrm{~s}$, but only data for the first second were included in the analysis. The first $100 \mathrm{~ms}$ were removed to avoid the contact artefact. For bumblebees, 2-6 sensilla were sampled per bee; for honeybees, 6-10 sensilla were sampled per bee.

Recording started when the open end of the electrode was placed over the tip of the sensillum. Individuals were repeatedly sampled in one of two protocols: (1) $50 \mathrm{mM}$ sucrose, $100 \mathrm{mM} \mathrm{KCl}$, water, $1 \mu \mathrm{M}$ neonicotinoid, $1 \mathrm{mM}$ neonicotinoid, $1 \mathrm{mM} \mathrm{NHT}, 100 \mathrm{mM} \mathrm{KCl}$, $50 \mathrm{mM}$ sucrose; or (2) $50 \mathrm{mM}$ sucrose, $50 \mathrm{mM}$ sucrose + neonicotinoid in one of the following concentrations $(1 \mathrm{nM}, 10 \mathrm{nM}, 1 \mu \mathrm{M}), 50 \mathrm{mM}$ sucrose. The neonicotinoids IMD, TMX, or CLO were used in each protocol. Neonicotinoid (Pestanal®, Sigma-Aldrich) solutions were prepared as serial dilutions starting with $1 \mathrm{mM}$ concentration. Sucrose and nicotine tartrate were purchased from Sigma-Aldrich and $\mathrm{KCl}$ from Fisher Scientific at purity $\geq 98 \%$. Demineralized water was used to prepare all solutions. Intervals between stimuli were $2-5 \mathrm{~min}$.

Recordings with IMD diluted in sucrose (Extended Data Figure 4) were further analysed using dbWave (http://perso.numericable.fr/frederic.marion-poll/deterrents/tk/dbwave/ index.htm). Predicted spiking neurons or 'units' were sorted from the digitally filtered signals according to their amplitude with the help of interactive software procedures. Electrophysiological recordings were then visually inspected to search for spike doublets, i.e. two spikes separated by an interspike interval shorter than the silent period ${ }^{36,37}$. Spike trains were analysed over $1 \mathrm{~s}$ following the first $100 \mathrm{~ms}$ removed to avoid the contact artefact.

\section{Electron microscopy}

Scanning electron microscopy was performed using a Cambridge Stereoscan 240 on samples that had been fixed with gluteraldehyde, washed in phosphate buffer then dehydrated through an ethanol gradient followed by a critical point dried. Specimens were then mounted on an aluminium stub with Acheson's silver dag before gold coating with a Polaron SEM coating unit.

\section{Statistics}

All analyses were performed using IBM SPSS $v$ 19. The mean total number of spikes in the electrophysiological recordings was analysed using repeated-measures analysis of variance (ANOVA) for each species with neonicotinoid as a main effect, sensillum number and bee as covariates, and stimulus as a repeated measure; a Levene's test was employed to test for equality of variance. Post hoc comparisons were pairwise t-tests with a Bonferroni adjustment for experiment-wise error rate. A two-way generalized linear model (GLM) was used to compare the behaviour of bees fed each of the neonicotinoid treatments for each bee species with least squares post hoc comparisons (Note: the sucrose-sucrose choice data were not included because of the requirements of GLM for factorial design). The difference in the amount eaten between the 2 food tubes in the behavioural choice assays was also analysed using a one-sample t-test against zero for each treatment; critical values were Bonferroniadjusted. The proportion of bees alive after $24 \mathrm{~h}$ was analysed using logistic regression 
(lreg). Each individual bee was entered in the analysis for the experiments with bumblebees and with honeybees. For the analysis with honeybees, 'cohort' was entered as a covariate.

\section{Extended Data}
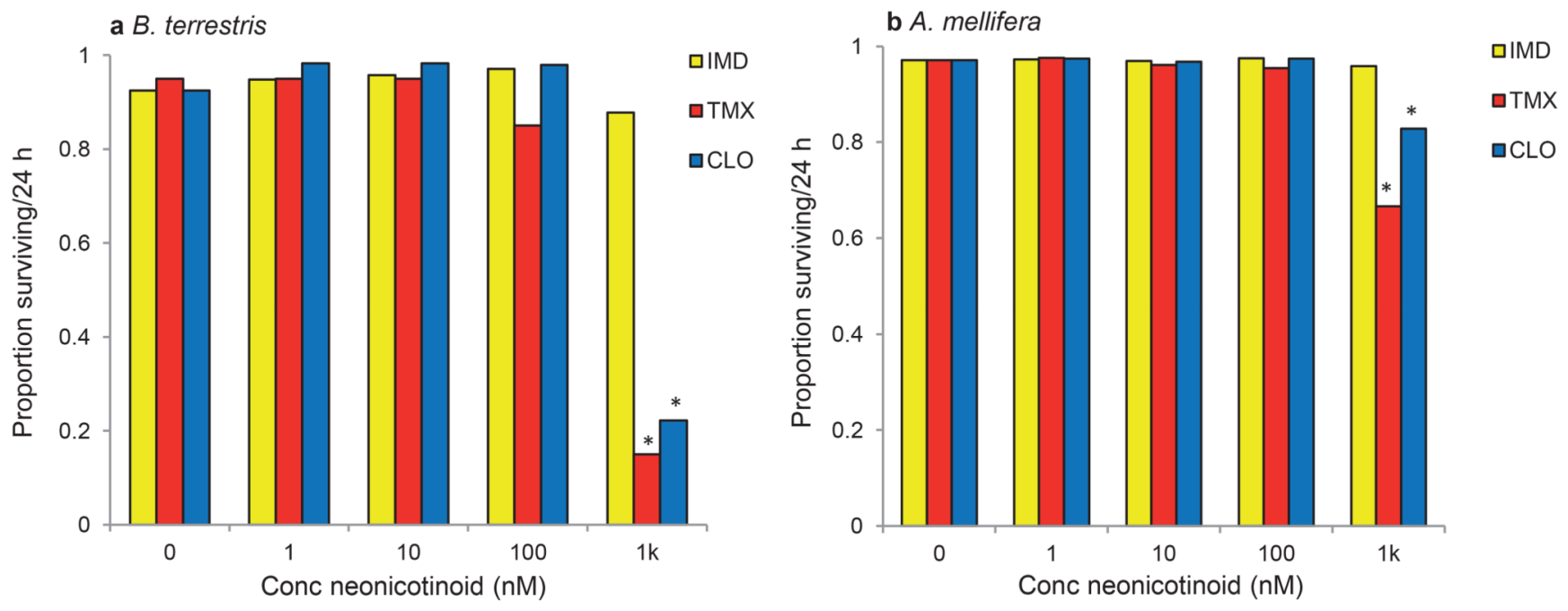

Extended Data Figure 1: The proportion of bees surviving after $24 \mathrm{~h}$ in the two-choice assay presented in Figure 1

a, Bumblebees given a choice between sucrose and sucrose laced with 1k nM TMX or CLO were less likely to survive after $24 \mathrm{~h}$ (lreg: IMD: $\chi_{4}{ }^{2}=4.36, \mathrm{P}=0.359$; TMX: $\chi_{4}{ }^{2}=62.3, \mathrm{P}$ $<0.001$; CLO: $\left.\chi_{4}{ }^{2}=79.7, \mathrm{P}<0.001\right)$. b. Honeybees given a choice between sucrose and sucrose laced with $1 \mathrm{k} \mathrm{nM} \mathrm{TMX} \mathrm{or} \mathrm{CLO} \mathrm{were} \mathrm{less} \mathrm{likely} \mathrm{to} \mathrm{survive} \mathrm{after} 24 \mathrm{~h}$ (lreg: IMD: $\chi_{4}^{2}=5.18, \mathrm{P}=0.269$; TMX: $\chi_{4}^{2}=577, \mathrm{P}<0.001$; CLO: $\chi_{4}^{2}=243, \mathrm{P}<0.001$ ). Cohort (cov) accounted for a significant portion of the variance in survival for all three treatment groups (lreg: IMD: $\chi_{1}^{2}=22.0, \mathrm{P}<0.001$; TMX: $\chi_{1}^{2}=32.4, \mathrm{P}<0.001$; CLO: $\chi_{1}^{2}=70.2, \mathrm{P}<0.001$ ). $*$ indicates $\mathrm{P}<0.05$ in least squares post hoc comparisons against sucrose in each treatment 

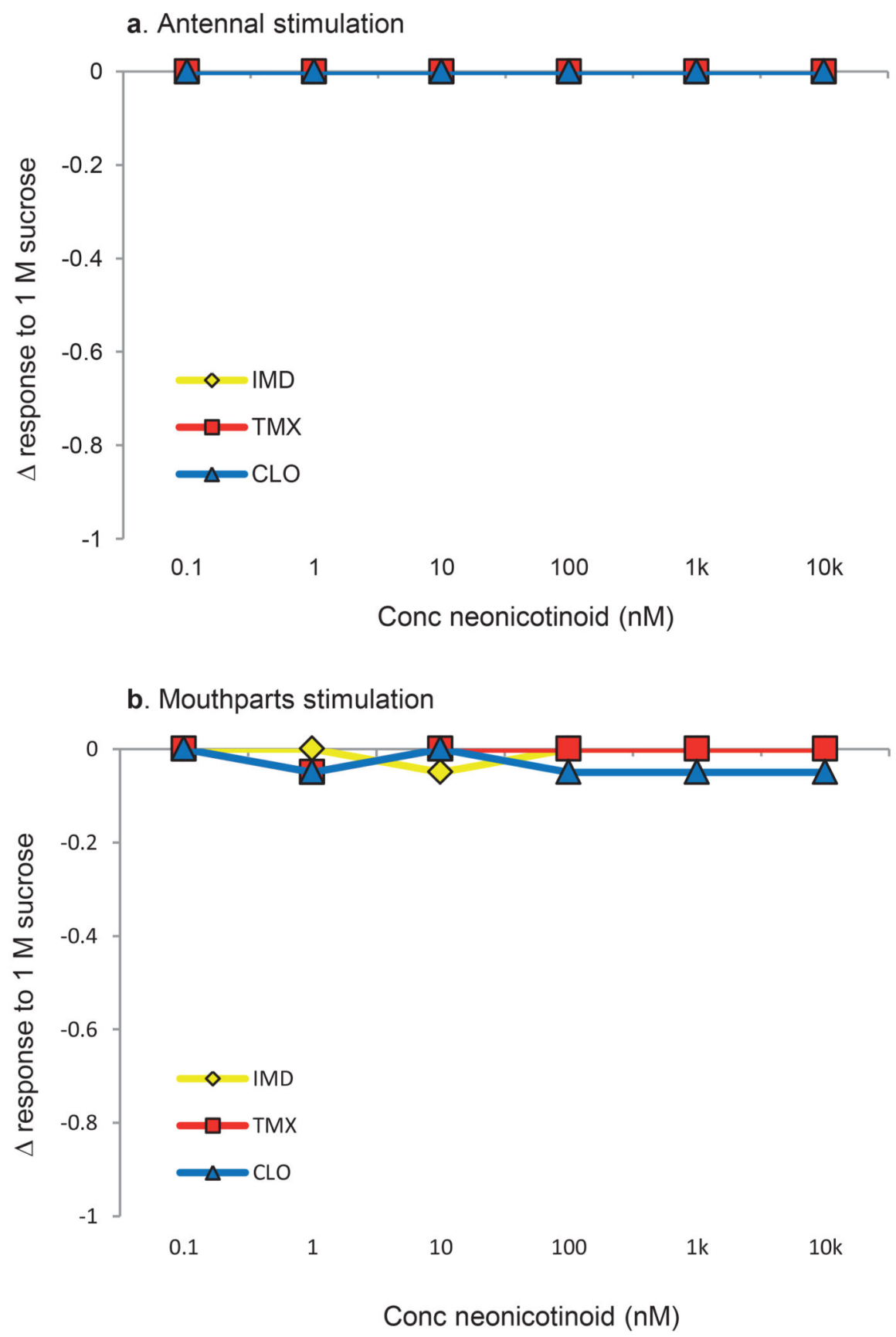

Extended Data Figure 2: Antennal proboscis extension response (PER) and mouthparts assay of honeybees to solutions containing neonicotinoids

a, Stimulation of the antennae with $1 \mathrm{M}$ sucrose solutions containing neonicotinoids did not affect the elicitation of PER. b, Honeybees did not refuse to consume solutions containing neonicotinoids; only one bee in the CLO treatments failed to drink the solutions. $\mathrm{N}=40$ / neonicotinoid treatment for antennal stimuli and $\mathrm{N}=10$ /each concentration of each neonicotinoid for the mouthparts taste assay. 


\section{a. Behavioural 2-choice assay}
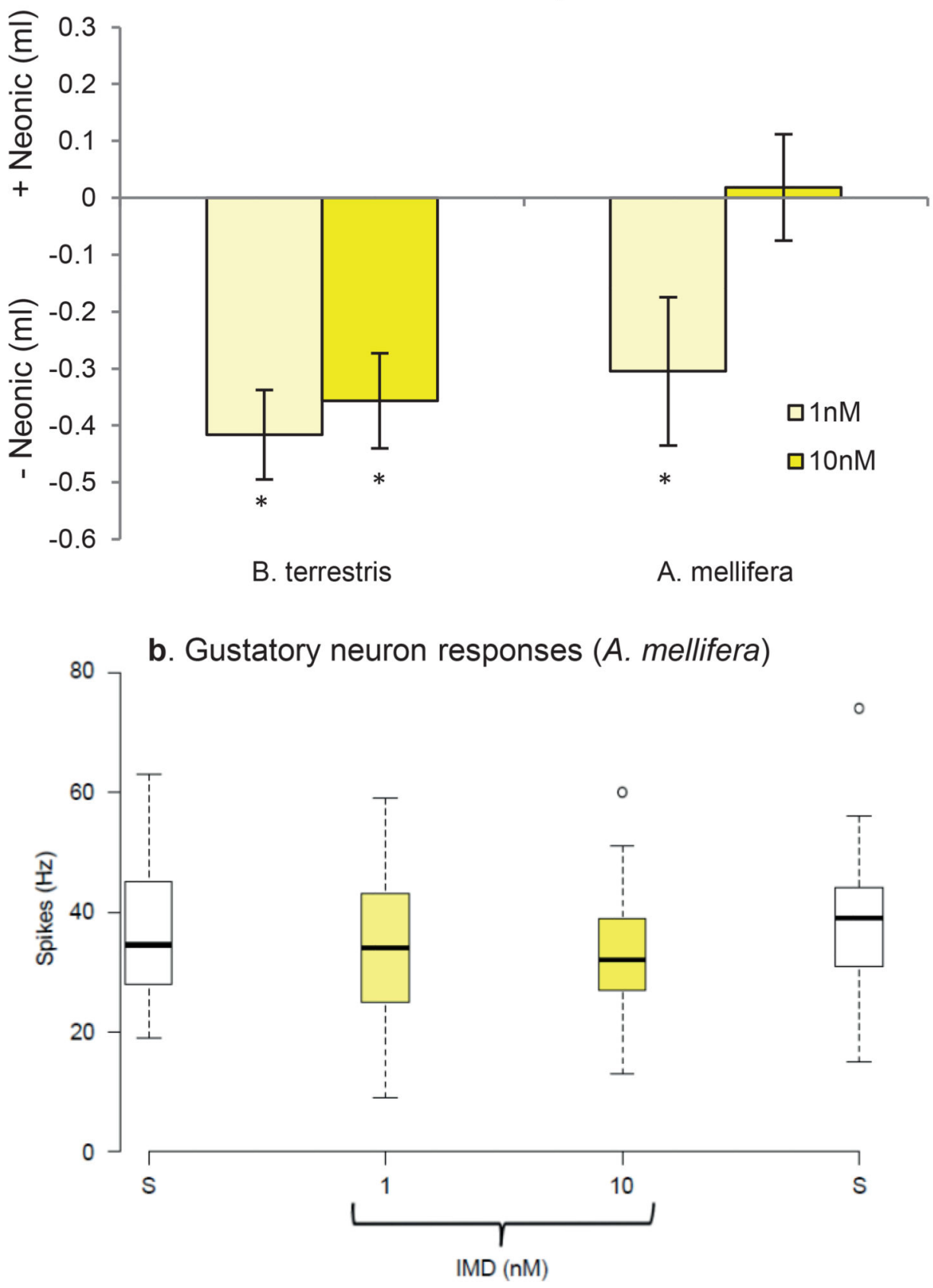

Extended Data Figure 3: Young bees avoid solutions containing neonicotinoids

a, Newly-emerged worker bumblebees $(\mathrm{N}=30$ bees/treatment $)$ and honeybees $(\mathrm{N}=20$ boxes/treatment) were tested in the behavioural choice assay with $1 \mathrm{nM}$ and $10 \mathrm{nM}$ IMD in sucrose solution as in Figure 2. Bumblebees avoided consuming both solutions containing IMD (one-sample t-test against 0, 1nM: $\mathrm{P}<0.001,10 \mathrm{nM}$ : $\mathrm{P}=0.001$ ), whereas honeybees avoided only the $1 \mathrm{nM}$ concentration (one-sample t-test against $0,1 \mathrm{nM}: \mathrm{P}=0.003,10 \mathrm{nM}: \mathrm{P}$ $=0.773$ ). Error bars represent \pm SE. b, The presence of IMD did not alter the spike frequency of gustatory neurons in the galeal sensilla of newly-emerged honeybees (repeated- 
measures ANOVA, stimulus: $\mathrm{F}_{1,47}=0.207, \mathrm{P}=0.653$ ). Recordings were made from the basiconic sensilla on the galea as in Figure 1. Boxplots represent the frequencies of responses to $50 \mathrm{mM}$ sucrose or to $50 \mathrm{mM}$ sucrose solutions containing $1 \mathrm{nM}$ or $10 \mathrm{nM}$ IMD. $\mathrm{N}=5$ bees, 10 sensilla/bee. Boxplots represent the median (black bars), the 1.5 interquartile range (whiskers) and outliers (circles). Stimuli on $\mathrm{x}$-axis are in order of presentation during the experiment.

a

\section{Sucrose}

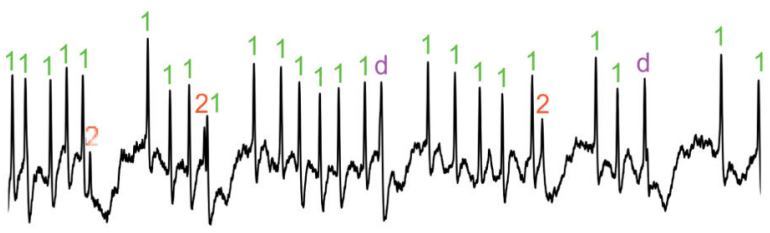

C

$$
\text { Sucrose + 1000nM IMD }
$$

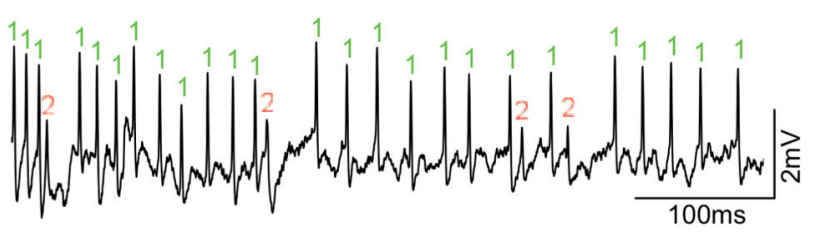

e

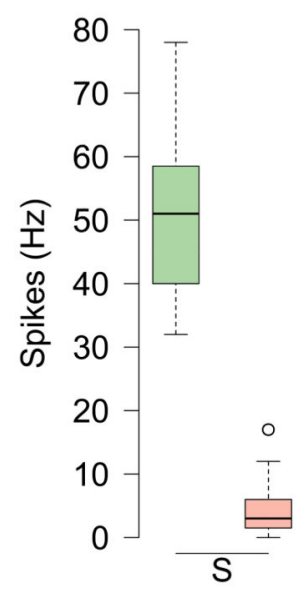

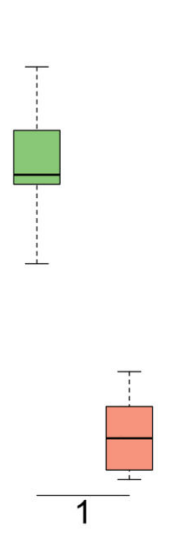

b

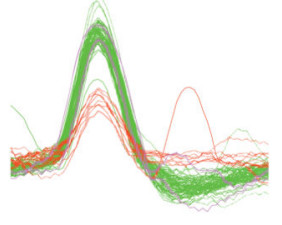

d

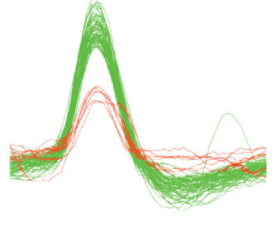

Extended Data Figure 4: Spike-sorted recordings for four of the honeybees in Figure 2

Nature. Author manuscript; available in PMC 2016 March 01. 
a, To verify that the spike rates we observed in Figure 2 were not a result in changes in the rates of firing of individual neurons, we spike sorted recordings from 4 honeybees. $\mathbf{b}$, Spike sorting revealed 2 potential spiking neurons (units) with different amplitudes that responded by eliciting spikes during sucrose stimulation. (This was also observed previously by Wright et al. $2010^{17}$ ). One neuron is labelled in green, the other in red. Spike doublets (indicated in pink as ' $d$ ') where both neurons spiked nearly simultaneously were also observed. c, d. These same two spiking neurons continued to respond when stimulated with sucrose containing 1uM IMD. e, Boxplots reveal that the rate of spiking was lower on average for one of the neurons (repeated-measures ANOVA, unit: $F_{1,36}=596, P<0.001$ ). The rate of firing of both neurons was not affected by IMD concentration (repeated-measures ANOVA, unit: $\mathrm{F}_{1,36}=0.369, \mathrm{P}=0.547$ ). Spikes from additional neurons (units) were not detected, and so we concluded that no other neurons were recruited during stimulation with IMD. ' $\mathrm{S}$ ' indicates stimulation with sucrose. Boxplots represent the median (black bars), the 1.5 interquartile range (whiskers) and outliers (circles). Stimuli on x-axis are in order of presentation during the experiment.

Extended Data Table 1:

Concentrations of neonicotinoids reported in floral nectar

\begin{tabular}{|c|c|c|c|c|c|c|c|c|c|}
\hline \multirow{2}{*}{ Source } & \multicolumn{3}{|c|}{ Imidacloprid } & \multicolumn{3}{|c|}{ Thiamethoxam } & \multicolumn{3}{|c|}{ Clothianidin } \\
\hline & $\mathbf{n g} / \mathrm{g}$ & PPB & $\mathbf{n M}$ & ng/g & PPB & $\mathbf{n M}$ & ng/g & PPB & $\mathbf{n M}$ \\
\hline Schmuck et al. $2001^{7}$ & 1.9 & 1.9 & 7.43 & - & - & - & - & - & - \\
\hline Pohorecka et al. $2012^{38}$ & 0.6 & 0.6 & 2.34 & 4.2 & 4.2 & 14 & 2.3 & 2.3 & 9.2 \\
\hline $\begin{array}{l}\text { Dively and Kamel } \\
2012^{6}\end{array}$ & $0.4-11$ & $0.4-11$ & $1.5-43$ & $8.2-9.5$ & $8.2-9.5$ & $28-37$ & - & - & - \\
\hline $\begin{array}{l}\text { Stoner and Eitzer } \\
2012^{38}\end{array}$ & 10 & 10 & 39 & 11 & 11 & 37 & - & - & - \\
\hline Byrne et al. $2013^{39}$ & $2.9-39$ & $2.9-39$ & $11-154$ & - & - & - & - & - & - \\
\hline Larson et al. $2013^{40}$ & - & - & - & - & - & - & 171 & 171 & 684 \\
\hline Pilling et al. $2013^{41}$ & - & - & - & $0.65-2.4$ & $0.65-2.4$ & $2.2-8.2$ & - & - & - \\
\hline Defra $2013^{42}$ & 0.13 & - & 0.5 & $1-3.9$ & $1-3.9$ & $3.4-13$ & $0.18-4$ & $0.18-4$ & $0.7-16$ \\
\hline
\end{tabular}

Extended Data Table 2:

Generalized linear models for the neonlcotlnold choice experiment and total food consumption in Figure 1

\begin{tabular}{|l|c|c|c|c|c|c|}
\hline B. terrestris & \multicolumn{3}{|c|}{ Choice test } & \multicolumn{3}{c|}{ Total food consumption } \\
\hline Between-subjects contrasts & df & $\chi^{\mathbf{2}}$ & P-value & df & $\chi^{\mathbf{2}}$ & P-value \\
\hline Concentration & 3 & 27.9 & $<\mathbf{0 . 0 0 1}$ & 3 & 263 & $<0.001$ \\
\hline Neonicotinoid & 2 & 12.1 & $\mathbf{0 . 0 0 2}$ & 2 & 150 & $<0.001$ \\
\hline Neonic $\times$ Conc & 6 & 7.97 & 0.240 & 6 & 47.7 & $<\mathbf{0 . 0 0 1}$ \\
\hline
\end{tabular}




\begin{tabular}{|l|c|c|c|c|c|c|}
\hline A. mellifera & \multicolumn{3}{|c|}{ Choice test } & \multicolumn{3}{c|}{ Total food consumption } \\
\hline Between-subjects contrasts & df & $\chi^{\mathbf{2}}$ & P-value & df & $\chi^{\mathbf{2}}$ & P-value \\
\hline Concentration & 3 & 4.93 & 0.176 & 3 & 37.1 & $<\mathbf{0 . 0 0 1}$ \\
\hline Neonicotinoid & 2 & 11.1 & $\mathbf{0 . 0 0 4}$ & 2 & 10.5 & $\mathbf{0 . 0 0 5}$ \\
\hline Neonic $\times$ Conc & 6 & 5.89 & 0.435 & 6 & 11.4 & 0.076 \\
\hline
\end{tabular}

Values in bold indicate interpreted model parameters. Note: sucrose-sucrose (control) data were not included.

Extended Data Table 3:

One-sample t-tests against ' 0 ' for each treatment of the $24 \mathrm{~h}$ behavioural assay in Figure 1

\begin{tabular}{|c|c|c|c|c|c|c|c|c|c|}
\hline \multicolumn{10}{|c|}{ B. terrestris } \\
\hline & & \multicolumn{2}{|c|}{ IMD } & & \multicolumn{2}{|c|}{ TMX } & & \multicolumn{2}{|c|}{ CLO } \\
\hline & $\mathbf{N}$ & $\mathbf{t}(\mathbf{d f})$ & P-value & $\mathbf{N}$ & $\mathbf{t}(\mathbf{d f})$ & P-value & $\mathbf{N}$ & $\mathbf{t}(\mathbf{d f})$ & P-value \\
\hline Sucrose & 55 & $-0.24(54)$ & 0.402 & & & & & & \\
\hline $\ln M$ & 57 & $5.13(56)$ & $<0.001 *$ & 38 & $3.11(38)$ & $0.002 *$ & 57 & $0.22(56)$ & 0.246 \\
\hline $10 \mathrm{nM}$ & 66 & $2.39(65)$ & 0.010 & 39 & $3.11(37)$ & $0.002 *$ & 59 & $0.26(58)$ & 0.183 \\
\hline $100 \mathrm{nM}$ & 65 & $2.33(64)$ & 0.012 & 36 & $1.31(35)$ & 0.099 & 48 & $0.09(47)$ & 0.465 \\
\hline $1 \mu \mathrm{M}$ & 66 & $-2.6(65)$ & 0.005 & 40 & $-1.15(39)$ & 0.128 & 62 & $-2.36(61)$ & 0.021 \\
\hline
\end{tabular}

\begin{tabular}{|c|c|c|c|c|c|c|c|c|c|}
\hline \multicolumn{10}{|c|}{ A. mellifera } \\
\hline & & \multicolumn{2}{|c|}{ IMD } & & \multicolumn{2}{|c|}{ TMX } & & \multicolumn{2}{|c|}{ CLO } \\
\hline & $\mathbf{N}$ & $\mathbf{t}(\mathbf{d f})$ & P-value & $\mathbf{N}$ & $\mathbf{t}(\mathbf{d f})$ & P-value & $\mathbf{N}$ & $t(d f)$ & P-value \\
\hline Sucrose & 40 & $-0.85(39)$ & 0.199 & & & & & & \\
\hline 1nM & 40 & $1.93(39)$ & 0.031 & 40 & $-0.32(39)$ & 0.376 & 40 & -0.288 & 0.387 \\
\hline $10 \mathrm{nM}$ & 40 & $1.75(39)$ & 0.044 & 40 & $3.80(39)$ & $<0.001 *$ & 40 & 0.882 & 0.191 \\
\hline $100 \mathrm{nM}$ & 40 & $2.97(39)$ & $0.002 *$ & 40 & $3.23(39)$ & $0.001 *$ & 40 & -0.221 & 0.414 \\
\hline $1 \mu \mathrm{M}$ & 40 & $2.00(39)$ & 0.026 & 40 & $3.25(39)$ & $0.001 *$ & 40 & 0.423 & 0.337 \\
\hline
\end{tabular}

P-values are for 1-tailed tests. P-values in bold are below $\mathrm{P}=0.05$.

Application of a Bonferroni adjustment criterion alters the $\mathrm{P}$-value threshold from $\mathrm{P}=0.05$ to $\mathrm{P}=0.002$. 


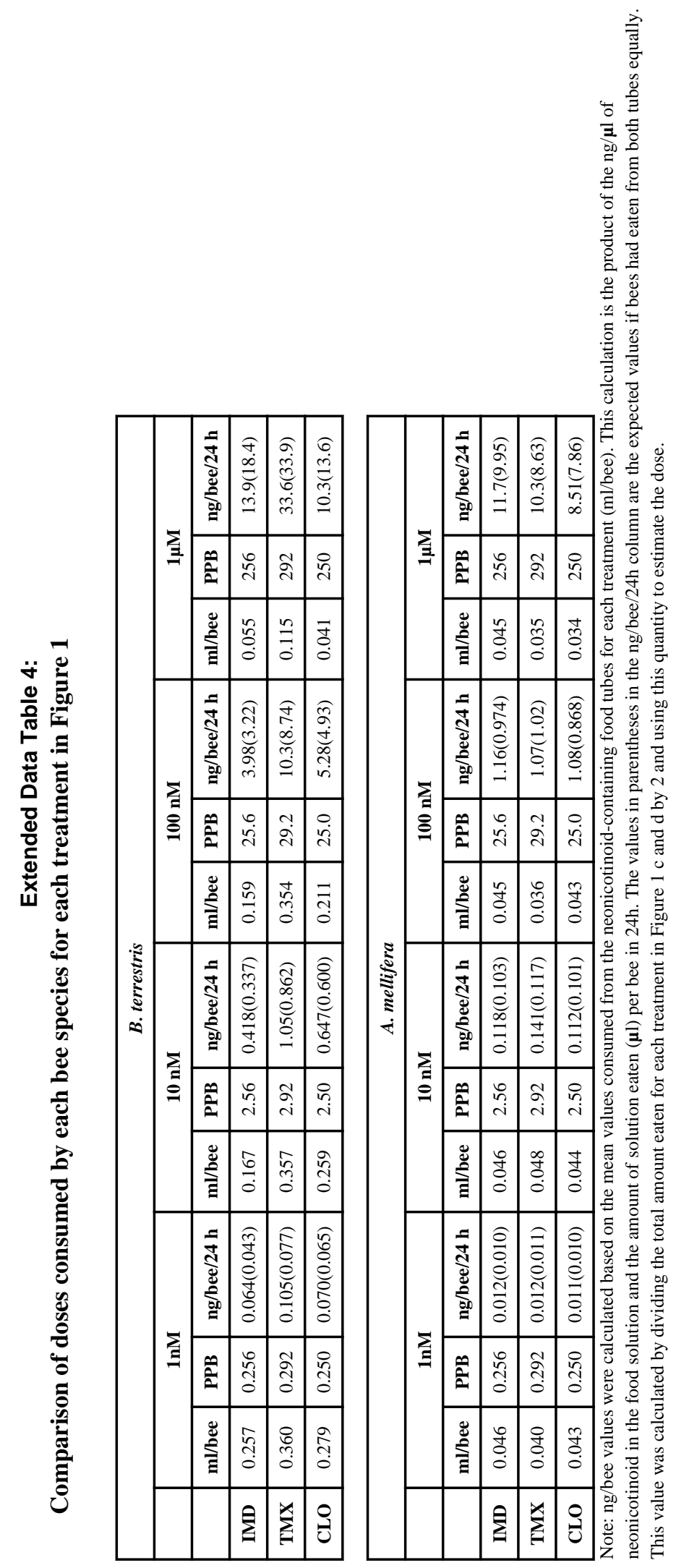

Nature. Author manuscript; available in PMC 2016 March 01. 
Extended Data Table 5:

\section{Repeated-measures ANOVA for Figure 2}

\begin{tabular}{|l|c|c|c|c|c|c|}
\hline B. terrestris & \multicolumn{3}{|c|}{ Water } & \multicolumn{3}{c|}{ Sucrose solution } \\
\hline Within subjects contrasts & df & F & P-value & df & F & P-value \\
\hline Stimulus & 1 & 8.60 & 0.004 & 1 & 0.579 & 0.449 \\
\hline Stimulus $\times$ bee (cov) & 1 & 4.45 & 0.038 & 1 & 1.23 & 0.271 \\
\hline Stimulus $\times$ sensillum (cov) & 1 & 0.038 & 0.846 & 1 & 0.558 & 0.458 \\
\hline Stimulus $\times$ neonicotinoid & 2 & 0.935 & 0.397 & 2 & 0.287 & 0.752 \\
\hline Error(stim) & 77 & & & 86 & & \\
\hline
\end{tabular}

\begin{tabular}{|l|c|c|c|c|c|c|}
\hline Between subjects contrasts & df & F & P-value & df & F & P-value \\
\hline Neonicotinoid & 2 & 10.2 & 0.937 & 2 & 0.004 & 0.996 \\
\hline Bee (cov) & 1 & 0.164 & 0.686 & 1 & 0.871 & 0.354 \\
\hline Sensillum (cov) & 1 & 5.63 & 0.020 & 1 & 3.35 & 0.071 \\
\hline Error & 77 & & & 86 & & \\
\hline
\end{tabular}

\begin{tabular}{|l|c|c|c|c|c|c|}
\hline A. mellifera & \multicolumn{3}{|c|}{ Water } & \multicolumn{3}{c|}{ Sucrose solution } \\
\hline Within subjects contrasts & df & F & P-value & df & F & P-value \\
\hline Stimulus & 1 & 95.6 & $<0.001$ & 1 & 7.47 & 0.007 \\
\hline Stimulus $\times$ bee (cov) & 1 & 4.20 & 0.042 & 1 & 5.31 & 0.023 \\
\hline Stimulus $\times$ sensillum (cov) & 1 & 0.303 & 0.583 & 1 & 0.142 & 0.707 \\
\hline Stimulus $\times$ neonicotinoid & 2 & 2.38 & 0.096 & 2 & 3.00 & 0.053 \\
\hline Error(stim) & 144 & & & 127 & & \\
\hline
\end{tabular}

\begin{tabular}{|l|c|c|c|c|c|c|}
\hline Between subjects contrasts & df & F & P-value & df & F & P-value \\
\hline Neonicotinoid & 2 & 1.23 & 0.295 & 2 & 6.70 & 0.002 \\
\hline Bee (cov) & 1 & 0.335 & 0.563 & 1 & 1.67 & 0.198 \\
\hline Sensillum (cov) & 1 & 1.37 & 0.244 & 1 & 12.6 & 0.001 \\
\hline Error & 144 & & 127 & & \\
\hline
\end{tabular}

For 'Water' model, the stimulus variable included: sucrose, $\mathrm{KCl}$, nicotine, water, $1 \mu \mathrm{M}$, and $1 \mathrm{mM}$ neonicotinoid. For the 'sucrose solution' model, the stimulus variable included: sucrose, $1 \mathrm{nM}, 100 \mathrm{nM}$, and $1 \mu \mathrm{M}$ neonicotinoid. The significant stimulus $\times$ neonicotinoid' term in the sucrose solution experiment for honeybees reflects a slight adaptive effect that occurred in the experiments with IMD, but not with TMX or CLO. Pairwise comparisons of each stimulus applied in the IMD experiment revealed that the $1 \mu \mathrm{M}$ IMD and the final sucrose control stimulus produced fewer spikes than the first sucrose stimulus $(\mathrm{P}=0.024$ and $\mathrm{P}=0.002)$. However, the $1 \mu \mathrm{M}$ IMD and the final sucrose stimulus were not significantly different $(\mathrm{P}=0.546)$ indicating either that the neurons in these experiments exhibited a slight adaptation effect or that the $1 \mu \mathrm{M}$ IMD concentration had a toxic effect that influenced the integrity of their responses to sucrose.

\section{Acknowledgments}

We thank Malcolm Thompson for beekeeping, Amy Radcliffe for help with experiments, and Candy Rowe, Scott Waddell, Mary Palmer, and Neil Millar for comments. This work was funded jointly by a grant from the BBSRC, NERC, the Wellcome Trust, Defra, and the Scottish Government under the Insect Pollinators Initiative (BB/ I000143/1) to GAW, a Leverhulme Trust research project grant (RPG-2012-708) to GAW, a Science Foundation Ireland grant (10/RFP/EOB2842) to JCS, a US National Science Foundation Graduate Research Fellowship awarded to EJT (Grant No. 2010097514), and an Irish Research Council's EMBARK Postgraduate Scholarship Scheme grant (RS/2010/2147) to EJT. 


\section{References}

1. Decourtye A, Devillers J. Ecotoxicity of neonicotinoid insecticides to bees. Adv Exp Med Biol. 2010; 683:85-95. [PubMed: 20737791]

2. Gill RJ, Ramos-Rodriguez O, Raine NE. Combined pesticide exposure severely affects individualand colony-level traits in bees. Nature. 2012; 491:105-109. [PubMed: 23086150]

3. Whitehorn PR, O'Connor S, Wackers FL, Goulson D. Neonicotinoid pesticide reduces bumble bee colony growth and queen production. Science. 2012; 336:351-352. [PubMed: 22461500]

4. Defra. An assessment of key evidence about neonicotinoids and bees. 2013.

5. Godfray HC, et al. A restatement of the natural science evidence base concerning neonicotinoid insecticides and insect pollinators. Proc Roy Soc B. 2014; 281 doi:10.1098/rspb.2014.0558. [PubMed: 24850927]

6. Dively GP, Kamel A. Insecticide residues in pollen and nectar of a cucurbit crop and their potential exposure to pollinators. J Agr Food Chem. 2012; 60:4449-4456. [PubMed: 22452667]

7. Schmuck R, Schoning R, Stork A, Schramel O. Risk posed to honeybees (apis mellifera 1, hymenoptera) by an imidacloprid seed dressing of sunflowers. Pest Manag Sci. 2001; 57:225-238. doi:10.1002/ps.270. [PubMed: 11455652]

8. Decourtye A, Devillers J, Cluzeau S, Charreton M, Pham-Delegue MH. Effects of imidacloprid and deltamethrin on associative learning in honeybees under semi-field and laboratory conditions. Ecotox Environ Safe. 2004; 57:410-419. [PubMed: 15041263]

9. Fischer J, et al. Neonicotinoids interfere with specific components of navigation in honeybees. PLoS ONE. 2014; 9:e91364. doi:10.1371/journal.pone.0091364. [PubMed: 24646521]

10. Henry M, et al. A common pesticide decreases foraging success and survival in honey bees. Science. 2012; 336:348-350. doi:10.1126/science.1215039. [PubMed: 22461498]

11. Laycock I, Lenthall KM, Barratt AT, Cresswell JE. Effects of imidacloprid, a neonicotinoid pesticide, on reproduction in worker bumble bees (bombus terrestris). Ecotoxicol. 2012; 21:19371945. [PubMed: 22614036]

12. Williamson SM, Willis SJ, Wright GA. Exposure to neonicotinoids influences the motor function of adult worker honeybees. Ecotoxicol. 2014; 23:1409-1418. doi:10.1007/s10646-014-1283-x. [PubMed: 25011924]

13. Carreck NL, Ratnieks FL. The dose makes the poison: Have "field realistic" rates of exposure of bees to neonicotinoid insecticides been overestimated in laboratory studies? J Apicult Res. 2014; 53:607-614.

14. Easton AH, Goulson D. The neonicotinoid insecticide imidacloprid repels pollinating flies and beetles at field-realistic concentrations. PLoS ONE. 2013; 8 doi: 10.1371/journal.pone.0054819.

15. Thompson HM, Wilkins S, Harkin S, Milnera S, Walters KFB. Neonicotinoids and bumblebees (bombus terrestris): Effects on nectar consumption in individual workers. Pest Manage Sci. 2014 doi: 10.1002/ps.3868. [PubMed: 25132051]

16. Tiedeken EJ, Stout JC, Stevenson PC, Wright GA. Bumblebees are not deterred by ecologically relevant concentrations of nectar toxins. J Exp Biol. 2014; 217:1620-1625. [PubMed: 24526720]

17. Wright GA, et al. Parallel reinforcement pathways for conditioned food aversions in the honeybee. Curr Biol. 2010; 20:2234-2240. [PubMed: 21129969]

18. Dethier, VG. The hungry fly. Harvard University Press; 1976.

19. Chapman RF, Ascolichristensen A, White PR. Sensory coding for feeding deterrence in the grasshopper schistocerca-americana. J Exp Biol. 1991; 158:241-259.

20. Weiss LA, Dahanukar A, Kwon JY, Banerjee D, Carlson JR. The molecular and cellular basis of bitter taste in drosophila. Neuron. 2011; 69:258-272. [PubMed: 21262465]

21. de Brito Sanchez MG, Giurfa M, Mota TRD, Gauthier M. Electrophysiological and behavioural characterization of gustatory responses to antennal 'bitter' taste in honeybees. Eur J Neurosci. 2005; 22:3161-3170. [PubMed: 16367782]

22. Dethier VG, Bowdan E. The effect of alkaloids on sugar receptors and the feeding-behavior of the blowfly. Physiol Entomol. 1989; 14:127-136. 
23. Sanchez MGD, et al. The tarsal taste of honey bees: Behavioral and electrophysiological analyses. Front Behav Neurosci. 2014; 8 doi: 10.3389/fnbeh.2014.00025. [PubMed: 24550801]

24. Singaravelan N, Nee'man G, Inbar M, Izhaki I. Feeding responses of free-flying honeybees to secondary compounds mimicking floral nectars. J Chem Ecol. 2005; 31:2791-2804. [PubMed: 16365705]

25. Brown LA, Ihara M, Buckingham SD, Matsuda K, Sattelle DB. Neonicotinoid insecticides display partial and super agonist actions on native insect nicotinic acetylcholine receptors. J Neurochem. 2006; 99:608-615. doi:10.1111/j.1471-4159.2006.04084.x. [PubMed: 16899070]

26. Dupuis JP, Gauthier M, Raymond-Delpech V. Expression patterns of nicotinic subunits alpha 2, alpha 7, alpha 8, and beta 1 affect the kinetics and pharmacology of ach-induced currents in adult bee olfactory neuropiles. J Neurophysiol. 2011; 106:1604-1613. [PubMed: 21734106]

27. Palmer MJ, et al. Cholinergic pesticides cause mushroom body neuronal inactivation in honeybees. Nature Commun. 2013; 4:1634. doi:10.1038/ncomms2648. [PubMed: 23535655]

28. Decourtye A, et al. Imidacloprid impairs memory and brain metabolism in the honeybee (apis mellifera 1.). Pestic Biochem Phys. 2004; 78:83-92.

29. Williamson SM, Wright GA. Exposure to multiple cholinergic pesticides impairs olfactory learning and memory in honeybees. J Exp Biol. 2013; 216:1799-1807. [PubMed: 23393272]

30. Feltham H, Park K, Goulson D. Field realistic doses of pesticide imidacloprid reduce bumblebee pollen foraging efficiency. Ecotoxicol. 2014; 23:317-323. [PubMed: 24448674]

31. Paoli PP, et al. Nutritional balance of essential amino acids and carbohydrates of the adult worker honeybee depends on age. Amino Acids. 2014; 46:1449-1458. doi:DOI 10.1007/ s00726-014-1706-2. [PubMed: 24623119]

32. Bitterman ME, Menzel R, Fietz A, Schafer S. Classical-conditioning of proboscis extension in honeybees (apis-mellifera). J Comp Psychol. 1983; 97:107-119. doi:Doi 10.1037/0735-7036.97.2.107. [PubMed: 6872507]

33. Whitehead AT, Larson JR. Ultrastructure of the contact chemoreceptors of apis mellifera 1. (Hymenoptera: Apidae). Intl J Insect Morphol and Embryol. 1976; 5:301-315.

34. Hodgson ES, Lettvin JY, Roeder KD. Physiology of a primary chemoreceptor unit. Science. 1955; 122:417-418. [PubMed: 13246649]

35. MarionPoll F, vanderPers J. Un-filtered recordings from insect taste sensilla. Entomol Exp Appl. 1996; 80:113-115.

36. Hiroi M, Meunier N, Marion-Poll F, Tanimura T. Two antagonistic gustatory receptor neurons responding to sweet-salty and bitter taste in drosophila. J Neurobiol. 2004; 61:333-342. [PubMed: 15389687]

37. Meunier N, Marion-Poll F, Rospars JP, Tanimura T. Peripheral coding of bitter taste in drosophila. J Neurobiol. 2003; 56:139-152. [PubMed: 12838579]

38. Pohorecka K, et al. Residues of neonicotinoid insecticides in bee collected plant materials from oilseed rape crops and their effect on bee colonies. J Apic Sci. 2012; 56:115-134.

39. Stoner KA, Eitzer BD. Using a hazard quotient to evaluate pesticide residues detected in pollen trapped from honey bees (apis mellifera) in connecticut. PLoS ONE. 2013; 8

40. Byrne F, V PK, Leimkuehler B, Fischer DB, Grafton-Cardwell EE, Morse JG. Determination of exposure levels of honey bees foraging on flowers of mature citrus trees previously treated with imidacloprid. Pest Manag Sci. 2013; 70:470-482. [PubMed: 23788449]

41. Larson JL, Redmond CT, Potter DA. Assessing insecticide hazard to bumble bees foraging on flowering weeds in treated lawns. PLoS ONE. 2013; 8

42. Pilling E, Campbell P, Coulson M, Ruddle N, Tornier I. A four-year field program investigating long-term effects of repeated exposure of honey bee colonies to flowering crops treated with thiamethoxam. PLoS ONE. 2013; 8

43. Thompson, H.; H, P.; Wilkins, S.; Pietravalle, S.; Sweet, D.; Jones, A. Effects of neonicotinoid seed treatments on bumble bee colonies under field conditions. Food and Enviroment Research Agency; Sand Hutton, York: 2013. 

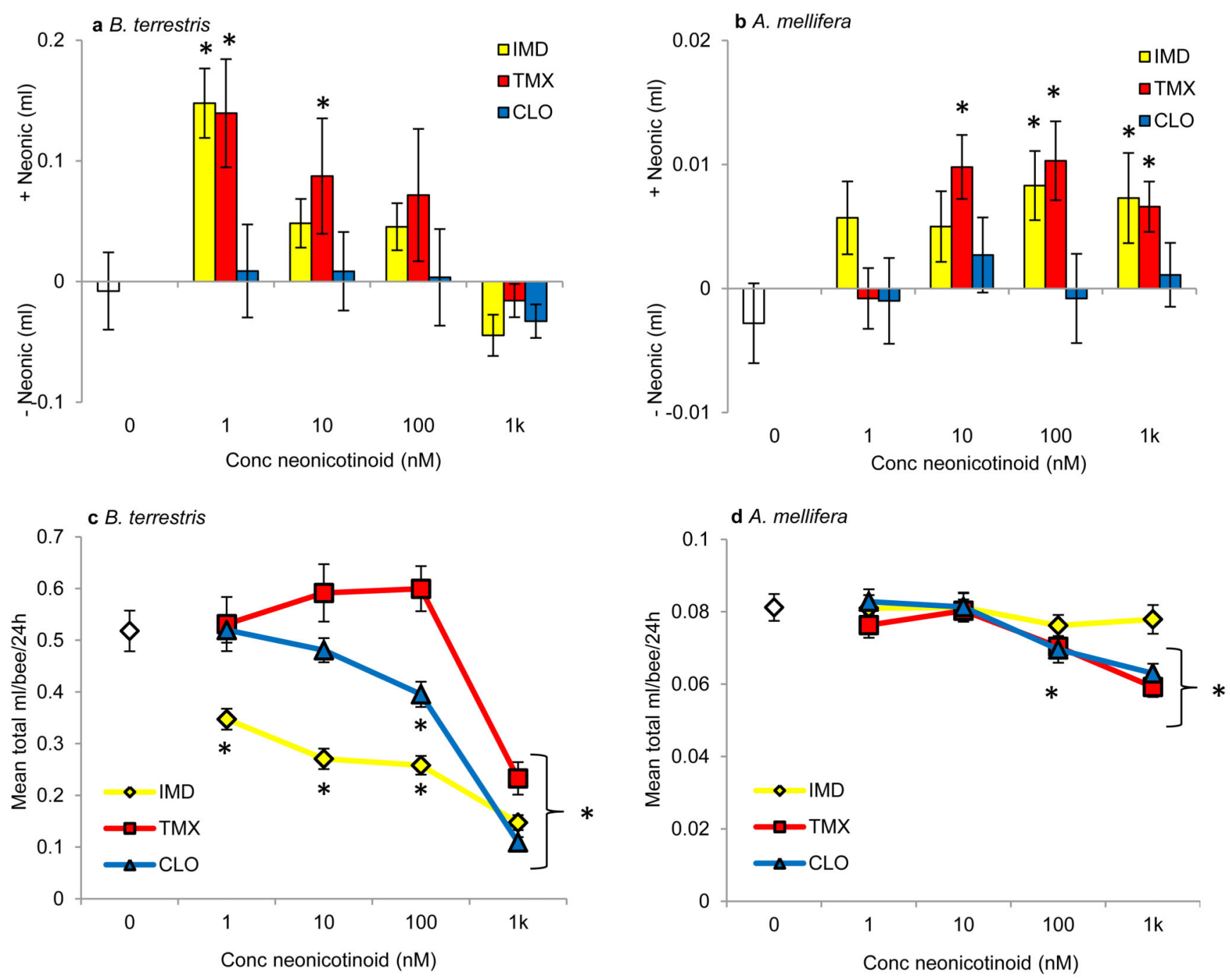

Figure 1. Foraging-age bees prefer to eat food containing neonicotinoids

a, Bumblebees and (b) honeybees given a choice of sucrose or sucrose containing a neonicotinoid pesticide chose to eat solutions containing IMD and TMX (Extended Data Table 2, bumblebees: GLM: $\chi_{2}{ }^{2}=12.1, \mathrm{P}=0.002$; honeybees: $\left.\chi_{2}{ }^{2}=11.1, \mathrm{P}=0.004\right)$. Data represent the difference in the amount consumed over $24 \mathrm{~h}$; positive values indicate a preference for solutions containing neonicotinoids. White bars indicate the sucrose control. Asterisks indicate $\mathrm{P} \leq 0.002$ (Bonferroni-adjusted critical value) for one-sample t-tests against the ' 0 ' value (indicating no preference, see Extended Data Table 3). Bumblebees: IMD: $1 \mathrm{nM}=57,10 \mathrm{nM}=66,100 \mathrm{nM}=65,1 \mu \mathrm{M}=66$; TMX: $1 \mathrm{nM}=38,10 \mathrm{nM}=39,100 \mathrm{nM}$ $=36,1 \mu \mathrm{M}=40$; $\mathrm{CLO}: 1 \mathrm{nM}=57,10 \mathrm{nM}=59,100 \mathrm{nM}=48,1 \mu \mathrm{M}=62$; honeybees: $\mathrm{N}=40$ cohorts of 25 bees/treatment. (c) The total amount of food eaten from both tubes by bumblebees was affected by the concentration and the presence of a neonicotinoid pesticide (GLM: $\chi_{6}^{2}=47.7, \mathrm{P}<0.001$, Extended Data Table 2) in one of the food tubes. (d) Honeybees ate less total food only when it contained $1 \mathrm{k} \mathrm{nM} \mathrm{TMX} \mathrm{or} \mathrm{CLO} \mathrm{(GLM:} \chi_{6}{ }^{2}=$ $10.5, \mathrm{P}=0.005$, Extended Data Table 2). White diamonds indicate amount eaten by sucrose 
control group. * indicates $\mathrm{P}<0.05$ in post hoc comparisons against sucrose. Error bars represent $\pm \mathrm{SE}$. 
B. terrestris

a

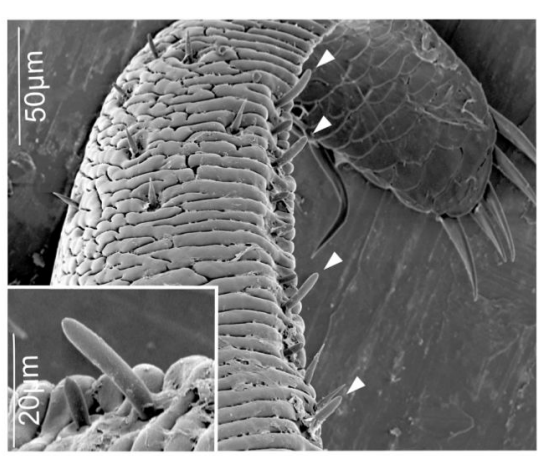

C

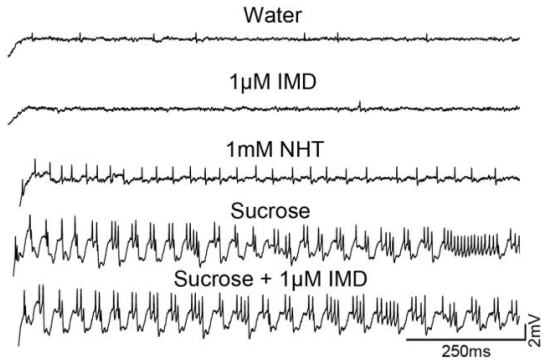

e

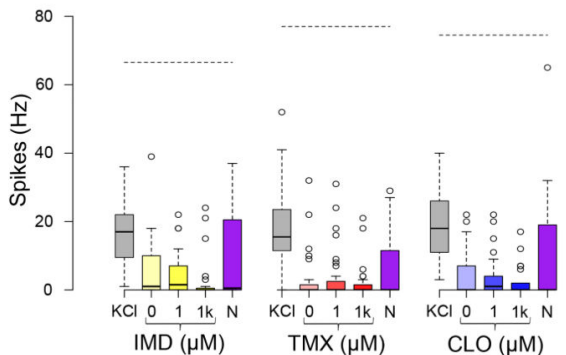

g

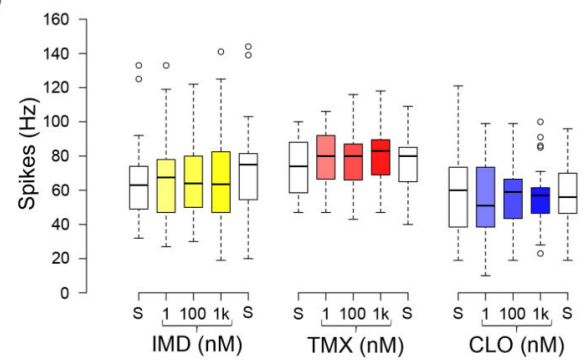

A. mellifera

b

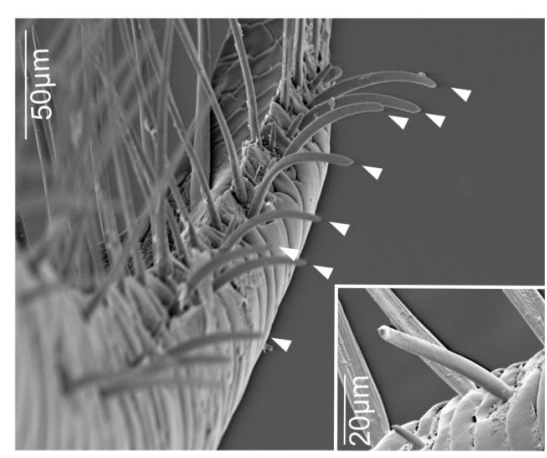

d

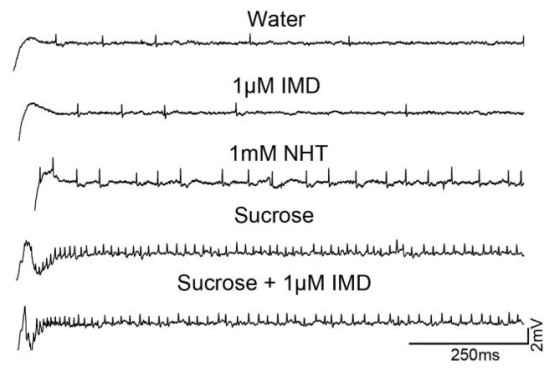

f

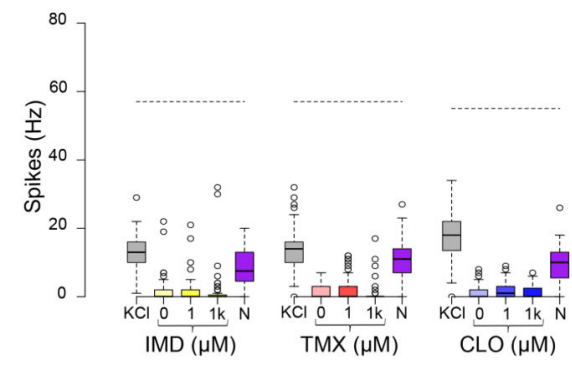

h

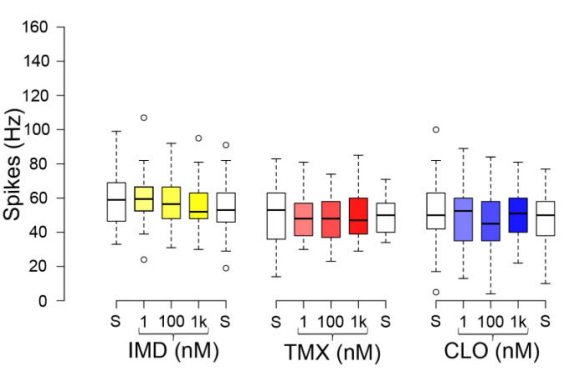

Figure 2. Electrophysiological recordings of the gustatory receptor neurons from the mouthparts of bumblebees and honeybees during stimulation with neonicotinoids

a, Scanning electron micrographs (SEM) of the galea (white arrows) of bumblebees and (b) honeybees. Recordings were made from the basiconic sensilla of the galea (white arrows); inserts are higher resolution SEM of individual sensilla. c, d. Spike trains recorded from both species reveal responses to NHT and to sucrose, but not to IMD. Boxplots of the spiking responses of gustatory neurons of the mouthparts of bumblebees (e) and honeybees (f) to $\mathrm{KCl}$, NHT and two concentrations of each of the neonicotinoids. Dashed lines 
represent the median response to $50 \mathrm{mM}$ sucrose. Solutions of the three neonicotinoids did not elicit activity from gustatory neurons greater than the response to water (indicated as ' 0 ' on X-axis) (Extended Data Table 5, ANOVA: bumblebees: $\mathrm{F}_{2,77}=0.935, \mathrm{P}=0.397$; honeybees: $F_{2,144}=2.38, P=0.096$ ). (Note: NHT elicited spike frequencies in gustatory neurons greater than those elicited by water in only $7 / 17$ of the bumblebees we tested, whereas NHT elicited spike frequencies greater than water in all of the honeybees tested). Bumblebees: $\mathrm{N}_{\mathrm{IMD}}=5 ; \mathrm{N}_{\mathrm{TMX}}=7 ; \mathrm{N}_{\mathrm{CLO}}=5$. Honeybees: $\mathrm{N}_{\mathrm{IMD}}=5 ; \mathrm{N}_{\mathrm{TMX}}=5 ; \mathrm{N}_{\mathrm{CLO}}=6$. $\mathbf{g}, \mathbf{h}$. The spiking response to sucrose was not reduced by the presence of the neonicotinoids at concentrations in the nectar-relevant range (Extended Data Table 5, ANOVA: bumblebees: $\mathrm{F}_{1,86}=0.579, \mathrm{P}=0.449$; honeybees: $\mathrm{F}_{1,127}=2.00, \mathrm{P}=0.053$ ). Bumblebees: $\mathrm{N}_{\text {IMD }}=8 ; \mathrm{N}_{\mathrm{TMX}}=5 ; \mathrm{N}_{\mathrm{CLO}}=6$. Honeybees: $\mathrm{N}_{\text {IMD }}=6 ; \mathrm{N}_{\mathrm{TMX}}=5 ; \mathrm{N}_{\mathrm{CLO}}=6$. Boxplots represent the median (black bars), the 1.5 interquartile range (whiskers) and outliers (circles). Stimuli on $\mathrm{x}$-axes of e-h are in order of presentation during the experiment. 